\title{
Japan okays test-tube baby gene tests
}

[TOKYO] Japan has taken its first step towards introducing preimplantation genetic diagnosis for human eggs that have been fertilized in vitro, with the approval last week by the Japan Society of Obstetrics and Gynaecology of guidelines covering such procedures.

The society's move ends a five-year standoff between members of the society and an anti-eugenics' patients' advocacy group over the approval of preimplantation genetic diagnosis. The procedure allows couples to ask for eggs used for in vitro fertilization (IVF) to be discarded if certain types of hereditary disorder are detected in the genes.

The society was last year forced to postpone the approval of guidelines for the genetic diagnosis of Duchenne's muscular dystrophy and fragile X syndrome in artificially fertilized eggs after opposition from the patients' advocacy group, which accused it of promoting discrimination against the disabled (see Nature 385, 763; 1997).

The new guidelines do not specify which diseases are to be tested for. The health ministry lists numerous hereditary disorders that can be detected by this method, but the guidelines say that each case will be assessed on its merits by a specialist committee of doctors and geneticists.
According to the guidelines, various factors will be assessed before the society gives approval for a genetic test, including the type of targeted disease, the genetic histories of the couple, and the facilities at institutions carrying out the test.

The society's existing ethical guidelines, which will now be modified, were drawn up in 1983 and restrict the use of IVF to treatments for infertility.

Kazuo Sato, president of the society, said in a statement that considerable discussion had been carried out with the public over the years, and that the guidelines, drawn up with special attention to the ethical issues surrounding preimplantation diagnosis, were intended to prevent misuse of the technique.

But members of the anti-eugenics patients' advocacy group, which represents more than 30 women's and disabled people's groups, complain that the society's decision has been rushed. One factor, they argue, was the recent furore over a doctor who successfully impregnated an infertile woman by IVF, using her husband's sperm and eggs donated by her sister. Such a practice is not allowed in Japan, as guidelines restrict IVF treatment to married couples, and prohibit the donation of ova and sperm from third parties.
Critics say the clinical application of reproductive techniques should be regulated by a more powerful body than the society. Members can only be expelled from the society if rules have been broken, and previous incidents have shown that the guidelines lack sufficient power of enforcement to prevent the abuse of techniques.

"The society made its decision rather abruptly, and discussions on the ethical and scientific issues seem to have been carried out in an ivory tower," complains Norio Fujiki, an emeritus professor of medical genetics at Fukui Medical School. "Discussions of bioethical issues related to medical techniques should not be confined to specialists - it should be debated on a national level."

Fujiki also says that preimplantation diagnosis should be regulated by law to prevent the risk of it being used for other purposes, such as selecting the sex of the child.

According to the Ministry of Health and Welfare, its council on health science plans to draw up new guidelines on reproductive techniques, including preimplantation diagnosis. But it says the potential social impact of the issue means it will need more time to consult the public.

AsakoSaegusa

\section{US think-tank queries cost of 'stockpile stewardship' programme}

[WASHINGTON] The costs of US nuclear weapons research - including those of its new 'stockpile stewardship' programme have been called into question by a report published last week. According to the report, the United States has spent $\$ 5,500$ billion on nuclear weapons since the start of the Manhattan project in 1940.

A 700-page study published by the Brookings Institution, Washington's preeminent liberal think-tank, says the cost of maintaining the US nuclear deterrent is now down to $\$ 35$ billion a year. Of this, $\$ 4.5$ billion is spent on 'stockpile stewardship', the programme designed to ensure the safety and reliability of US nuclear weapons.

Pointing out that annual expenditure on “activities now called stockpile stewardship" averaged $\$ 3.6$ billion (in 1996 dollars)

between 1948 and 1991, the study, entitled Atomic Audit, questions why the programme's budget is higher than it was during the Cold War.

William Weida, professor of economics at Colorado College in Colorado Springs, and co-author of the report, argues that the programme has "huge amounts of money for construction projects which appear only to be intended to ensure continued employment at the national laboratories".

He is already working on a further study

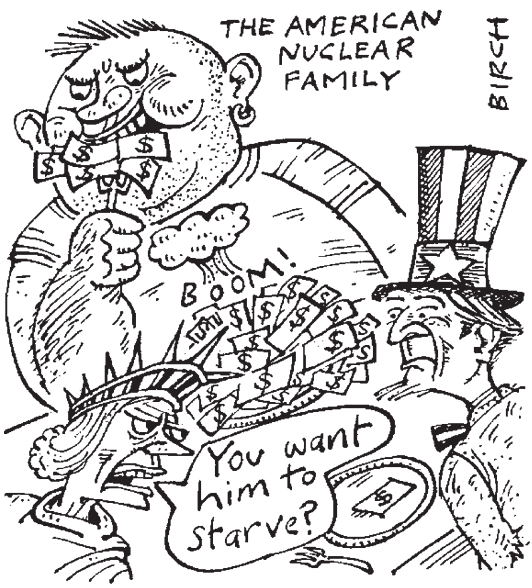

that will "conservatively estimate" that stockpile stewardship "could be done for half or less" of the budget that the Department of Energy has allocated to it.

But Robin Staffin, deputy assistant secretary for nuclear weapons research at the Department of Energy, says the stewardship programme "is balanced, prudent and cost-effective".

Congressional appropriators in both houses have recently agreed to fund the programme next year at the requested level of $\$ 4.5$ billion. But Weida says the proposed budget for stockpile stewardship includes large amounts of money for construction projects "whose uses are not yet specific, but which will evidently be dreamt up later" by the nuclear weapons laboratories.

Although the Clinton administration has said that the programme will cost $\$ 45$ billion over the next ten years, construction costs of planned facilities tail off after the year 2003, leaving hundreds of millions of dollars for additional facilities.

Staffin argues that it is normal for the Department of Energy to reserve money in its budget projections for undefined construction projects. He adds that the department is exploring the need for various such facilities, although it has not yet given its backing to any.

One proposal is a successor to the DualAxis Radiographic Hydrodynamic Test facility at the Los Alamos Laboratory in New Mexico. Another is a pulsed-power fusion device at the Sandia Laboratory, planned for possible construction on the mothballed nuclear weapons test site in Nevada.

More than half of the money Brookings says has been spent on nuclear weapons since $1940-\$ 3,200$ billion - has gone on deploying weapons systems. Research, development and production has cost $\$ 410$ billion; the clean-up of nuclear facilities has consumed just $\$ 45$ billion. Colin Macilwain 